\title{
HUBUNGAN CUSTOMER VALUE DENGAN KEPUTUSAN PENGAMBILAN KREDIT PADA PT. SMS FINANCE BENGKULU
}

\author{
Herli Widani, Rinto Noviantoro \\ Program Studi Manajemen Fakultas Ekonomi Universitas Dehasen Bengkulu \\ rintonoviantoro@yahoo.co.id
}

\begin{abstract}
ABSTRAK
Herli Widani, Rinto Noviantoro; Tujuan penelitian ini mengetahui hubungan customer value dengan keputusan pengambilan kredit PT. SMS Finance Bengkulu. Metode analisis yang digunakan adalah korelasi Spearman Rank dan Uji hipotesis. Berdasarkan perhitungan koefisien korelasi, nilai rho hitung $(\rho)$ sebesar 0,829 berada pada interval koefisien korelasi antara 0,800-1,000, tingkat hubungan yang sangat kuat, artinya hubungan customer value dengan keputusan pengambilan kredit pada PT. SMS Finance Bengkulu adalah sangat kuat. Berdasarkan uji hipotesis diperoleh nilai rho hitung lebih besar dari rho table $(0,829>0,364)$ sehingga Ho ditolak dan Ha diterima, artinya ada hubungan yang signifikan antara customer value dengan keputusan pengambilan kredit pada PT. SMS Finance Bengkulu.
\end{abstract}

\begin{abstract}
Herli Widani, Rinto Noviantoro; This study aims to determine the relationship between customer value and decision for withdrawal of credit in PT. SMS Finance Bengkulu. The analysis method was used Spearman Rank correlation and hypothesis test.

Based on the calculation of correlation coefficient, the value of rho count $(\rho)$ of 0.829 is in the correlation coefficient interval between $0.800-1000$, the level of relationship is very strong, it means that the relationship between customer value and the decision of withdrawal of credit in PT. SMS Finance Bengkulu is very strong. Based on hypothesis test rho value calculated rho table $(0.829>0.364)$ so that Ho is rejected and $\mathrm{Ha}$ is accepted, it means that there is a significant relationship between customer value and the decision for withdrawal credit in PT. SMS Finance Bengkulu.
\end{abstract}

Key Words: Customer Value, Keputusan Pengambilan Kredit.

\section{LATAR BELAKANG}

Customer value yang lebih baik akan mendorong konsumen untuk memutuskan memilih produk perusahaan, sehingga diketahui bahwa customer value yang buruk akan membuat konsumen menjadi kecewa jika harapan dan kinerja yang dirasakan dari produk perusahaan tidak sesuai dengan ekspektasi yang diharapkan oleh konsumen. Menghasilkan customer value yang baik pada sebuah perusahaan bukanlah hal yang mudah untuk dilakukan oleh perusahaan, ini dikarenakan banyaknya persaingan perusahaan yang mampu mengubah selera ataupun minat konsumen ke produk perusahaan lain yang dianggap lebih menarik.

Salah satu perusahaan yang berupaya mendorong nilai konsumennya menjadi lebih superior dari perusahaan lain adalah PT. SMS Finance Bengkulu, PT. SMS Finance Bengkulu merupakan sebuah perusahaan jasa yang bergerak dibidang finance yang berada di Kota Bengkulu, PT. SMS Finance Bengkulu memiliki sangat banyak kompetitor di Kota Bengkulu yang sudah memiliki nama cukup besar dibandingkan oleh PT. SMS Finance Bengkulu, maka dari itu penerapan penilaian konsumen yang superior sangat sulit dilakukan.

PT. SMS Finance Bengkulu memiliki masalah atas perusahaan finance pendahulu yang ada di Kota Bengkulu yang jauh lebih terkenal di kalangan masyarakat Kota Bengkulu, sehingga PT. SMS Finance Bengkulu harus benar-benar melakukan upaya keras untuk mendapat nilai yang baik bagi nasabah maupun calon nasabahnya sehingga calon nasabah bersedia untuk memutuskan pengambilan kredit pada PT. SMS Finance Bengkulu. PT. SMS Finance Bengkulu harus berupaya untuk menyampaikan informasi yang akurat kepada calon nasabah maupun nasabah yang ada dibandingkan dengan pesaing.

Nilai konsumen yang dimaksud tidak semata mengenai kualitas produk yang ditawarkan oleh PT. SMS Finance Bengkulu namun juga hal lainnya, Sweeny dan Soutar dalam Priansa (2016:111) menyatakan bahwa dimensi nilai terdiri dari empat aspek utama yaitu:

1. Emotional value : berkaitan dengan utilitas yang berasal dari perasaan atau emosi positif yang ditimbulkan dari mengkonsumsi produk. 
2. Social value : berkaitan dengan utilitas yang didapatkan dari kemampuan produk untuk meningkatkan konsep diri-sosial konsumen.

3. Quality/performance value : berkaitan dengan utilitas yang didapatklan dari produk karena reduksi biaya jangka pnduk dan biaya jangka panjang.

4. Price/value for money : berkaitan dengan utilitas yang diperoleh dari persepsi terhadap kualitas dan kinerja yang diharapkan atas produk

Keempat dimensi penilaian dari konsumen tersebut haruslah positif dan berjalan sesuai dengan harapan PT. SMS Finance Bengkulu, sehingga nasabah PT. SMS Finance Bengkulu merasakan bahwa produk yang disediakan oleh PT. SMS Finance Bengkulu telah sesuai dan pantas untuk percaya untuk melakukan pengambilan kredit yang diharapkan oleh nasabah.

\section{LANDASAN TEORI Customer Value}

Berbagai pakar berusaha untuk memahami apa yang dimaksud dengan customer value berdasarkan sudut pandangnya masing-masing. Albrecht dalam Priansa (2016:90) menyatakan bahwa customer value: merupakan suatu persepsi dari konsumen terhadap pemenuhan kebutuhan tertentu. Nilai adalah akhir dari solusi yang diterima oleh konsumen. Jika dipelajari lebih lanjut customer value tersebut memiliki suatu tingkatan-tingkatan yang membentuknya.

Neumann dalam Priansa (2016:97) menyatakan bahwa: " The most important success factor for a firm is the ability to deliver better customer value than the competition". Dalam persaingan yang semakin ketat saat ini, suatu badan usaha harus dapat memberikan suatu nilai yang lebih baik kepada konsumen daripada pesaing-pesaingnya. Oleh karena itu customer value penting bagi setiap badan usaha. Treacy dan Wiersema dalam Priansa (2016:98) menyatakan bahwa: Customer value merupakan jumlah dari manfaat yang diterima oleh konsumen dikurangi dengan biaya-biaya yang dikeluarkan untuk mendapatkan suatu produk atau jasa. Manfaat-manfaat tersebut akan menciptakan customer value bagi konsumen, sedangkan biaya-biaya yang dikeluarkan oleh konsumen akan mengurangi customer value.

Nilai (value) dari suatu produk dapat didefinisikan sebagai rasio antara apa yang konsumen dapatkan dan apa yang konsumen berikan. Konsumen mendapatkan kegunaan dari suatu produk dan "memberikan" biaya. Kegunaan disini termasuk di dalamnya adalah kegunaan fungsional dan juga kegunaan emosional. Sedangkan yang termasuk ke dalam biaya adalah biaya moneter (uang), biaya Waktu, biaya tenaga, dan biaya fisik (Kotler dan Keller, 2012:220). Secara matematis, pengertian tersebut dapat dirumuskan dalam persamaan sebagai berikut:

$$
\begin{aligned}
\text { nilai }(\text { value }) & =\frac{\text { kegunaan }}{\text { biaya }} \\
& =\frac{\text { kegunaan fungsional }+ \text { kegunaan emosional }}{\text { biaya moneter }+ \text { biaya waktu }+ \text { Biaya Tenaga }+ \text { Biaya Psikis }}
\end{aligned}
$$

Hilangnya kesempatan untuk memperoleh keuntungan, mengisyaratkan bahwa kondisi tersebut perlunya perusahaan untuk meningkatkan nilai konsumen. Untuk itu perusahaan perlu melakukan kreasi atau penciptaan nilai yang mampu menarik hati konsumen, sehingga konsumen mau membayar dengan tingkat tarif atau harga yang menguntungkan bagi perusahaan. Konsumen membeli sesuatu dilakukan berdasarkan kebutuhan tertentu dan mengharapkan produk tersebut sesuai dengan harapannya. Mereka mengevaluasi beberapa penawaran dan mengambil keputusan yang terbaik. Konsumen akan mengkonsumsi produk dari perusahaan yang dalam persepsi mereka menawarkan nilai terhantar pada konsumen (customer delivered value) paling tinggi. Untuk membantu organisasi bisnis dalam menciptakan superior customer value.

\section{Keputusan Pembelian}

Menurut Griffin (2007:38) keputusan konsumen/nasabah dalam mengambil kredit adalah suatu tindakan memilih satu alternatif dari serangkaian alternatif yang ada. Menurut Schiffman dan Kanuk dalam Kuncoro dan Adithya (2010:88) keputusan nasabah dalam mengambil kredit adalah pemilihan dari dua atau lebih alternatif pilihan keputusan pengambilan kredit, artinya bahwa seseorang dapat membuat keputusan, haruslah tersedia alternatif lainnya.

Menurut Tjiptono (2010:156) keputusan pembelian yang dilakukan oleh konsumen merupakan tindakan individu yang secara langsung atau tidak langsung terlibat dalam usaha memperoleh dan menggunakan suatu produk atau jasa yang dibutuhkan sedangkan menurut Kotler dalam alih bahasa 
Teguh dan Ronny (2002:204), Keputusan pembelian merupakan serangkaian proses yang dilalui konsumen dalam memutuskan tindakan pembelian.

\section{Pengertian Kredit}

Kredit berasal dari bahasa Yunani, yaitu "credere" atau "credo" yang berarti kepercayaan (trust atau faith). Oleh karena itu dasar dari kegiatan pemberian kredit dari yang memberikan kredit kepada yang menerima kredit adalah kepercayaan. Transaksi kredit timbul karena suatu pihak meminjam sejumlah uang atau sesuatu yang dipersamakan dengan itu, di mana pihak peminjam wajib melunasi hutangnya atau rekeningnya tersebut pada waktu yang telah ditentukan. Disamping itu kredit pun timbul sebagai akibat adanya transaksi jual beli, dimana pembayarannya ditangguhkan, baik sebagian maupun seluruhnya.

Menurut Undang-Undang perbankan nomor 10 tahun 1998, kredit adalah penyaluran uang atau tagihan yang dapat dipersamakan dengan itu, berdasarkan persetujuan atau kesepakatan pinjam meminjam antara bank dengan pihak lain yang mewajibkan pihak peminjam melunasi hutangnya setelah jangka waktu tertentu dengan pemberian bunga.

Sedangkan pengertian kredit menurut Eric L. Kohler dalam Mulyono (2007:9): "Kredit adalah kemampuan untuk melaksanakan suatu pembelian atau mengadakan suatu pinjaman dengan suatu janji pembayarannya akan dilakukan dan ditangguhkan pada suatu jangka waktu yang disepakati".

\section{Kerangka Analisis}

\begin{tabular}{|l|l|}
$\begin{array}{l}\text { Customer Value }(\mathrm{X}): \\
\text { 1. Emotional value } \\
\text { 2. Social value } \\
\text { 3. Quality/performance value } \\
\text { 4. Price/value for money } \\
\begin{array}{l}\text { (Sweeny dan Soutar dalam } \\
\text { Priansa, 2016:111) }\end{array}\end{array} \quad \rightarrow \begin{array}{ll}\text { Keputusan Pengambilan Kredit (Y) : } \\
1 . & \text { kesadaran, } \\
2 . & \text { identifikasi alternatif, } \\
3 . & \text { menilai alternatif, } \\
4 . & \text { keputusan membeli, } \\
5 . & \text { dan perilaku setelah pembelian } \\
\text { (Manap, 2016:248). }\end{array}$ \\
\hline
\end{tabular}

Gambar 1. Kerangka Analisis

\section{HASIL PENELITIAN DAN PEMBAHASAN}

\section{Hubungan Cutomer Value dengan Keputusan Pengambilan Kredit pada PT. SMS Finance Bengkulu}

Untuk menganalisis hubungan antara customer value dengan keputusan pengambilan kredit nasabah PT. SMS Finance Bengkulu melalui jawaban yang diberikan responden dari pernyataanpernyataan yang menyangkut customer value dan keputusan pengambilan kredit nasabah PT. SMS Finance Bengkulu dalam kuesioner, maka peneliti menggunakan analisis korelasi rank spearman. Data yang digunakan dalam korelasi rank spearman harus merupakan data ordinal dalam bentuk ranking yang diperoleh dari skor jawaban responden sebagaimana terlampir pada lampiran 2 - 6. Setelah diketahui nilai $b_{i}^{2}$ (lampiran 6) maka dapat dihitung nilai korelasi antara kedua variabel yang diteliti.

Berdasarkan lampiran 6, diketahui bahwa nilai $b_{i}{ }^{2}$ adalah 769,5 dengan jumlah $\mathrm{n}=30$ sehingga dapat dihitung nilai koefisien korelasi rank spearman sebagai berikut :

$$
\rho=1-\frac{6 \sum b_{i}{ }^{2}}{n\left(n^{2}-1\right)}
$$




$$
\begin{aligned}
& =1-\frac{6(769,5)}{30\left(30^{2}-1\right)} \\
& =1-\frac{4617}{30(900-1)} \\
& =1-\frac{4617}{26970} \\
& =1-0,171 \\
& =0,829
\end{aligned}
$$

Dari hasil analisis korelasi rank spearman diketahui bahwa nilai $\rho$ (rho) hitung adalah 0,829 berada pada interval interprestasi korelasi $0.800-1,000$, tingkat hubungan yang sangat kuat. Artinya hubungan customer value dengan keputusan pengambilan kredit pada PT. SMS Finance Bengkulu adalah sangat kuat.

\section{Uji Hipotesis}

Untuk menentukan diterima atau ditolaknya hipotesis yang diajukan maka dibandingkan antara nilai rho hitung dengan rho tabel, kemudian dikonsultasikan dengan kriteria pengujian hipotesisnya dengan ketentuan sebagai berikut:

1) Penentuan level of significant $95 \%$ atau alpha $(\alpha) 5 \%$

2) $\mathrm{H}_{\mathrm{o}}$ ditolak dan $\mathrm{H}_{\mathrm{a}}$ diterima ; Jika nilai rho hitung $>$ dari rho tabel, artinya ada hubungan yang signifikan antara customer value dengan keputusan pengambilan kredit pada PT. SMS Finance Bengkulu.

3) $\mathrm{H}_{\mathrm{o}}$ diterima dan $\mathrm{H}_{\mathrm{a}}$ ditolak ; Jika nilai rho hitung < dari rho tabel artinya tidak terdapat hubungan yang signifikan antara customer value dengan keputusan pengambilan kredit pada PT. SMS Finance Bengkulu.

Berdasarkan hasil perhitungan diperoleh nilai rho hitung $(\rho)$ sebesar 0,829 sedangkan rho tabel 0,364 (terlampir) atau 0,829 > 0,364 sehingga Ho ditolak dan Ha diterima, artinya terdapat hubungan yang signifikan antara customer value dengan keputusan pengambilan kredit pada PT. SMS Finance Bengkulu.

\section{Pembahasan}

Berdasarkan hasil analisis yang telah dilakukan maka diketahui bahwa nilai rho hitung $(\rho)$ adalah 0,829 berada pada interval interprestasi korelasi $0,800-1,000$, tingkat hubungan yang sangat kuat. Artinya hubungan customer value dengan keputusan pengambilan kredit pada PT. SMS Finance Bengkulu adalah sangat kuat dan nilai rho hitung $(\rho)>$ dari rho tabel $(0,829>0,364)$ sehingga Ho ditolak dan Ha diterima, artinya ada hubungan yang signifikan antara customer value dengan keputusan pengambilan kredit pada PT. SMS Finance Bengkulu.

PT. SMS Finance Bengkulu merupakan sebuah perusahaan jasa yang bergerak di bidang keuangan (finance), sehingga sumber pendapatan PT. SMS Finance Bengkulu merupakan seberapa besar nasabah yang diperoleh oleh PT. SMS Finance Bengkulu sehingga nasabah akan memberikan timbal balik berupa bunga kredit atas pinjaman kredit yang dikucurkan oleh PT. SMS Finance Bengkulu.

Banyaknya kompetitor yang ada di Kota Bengkulu, membuat PT. SMS Finance Bengkulu harus memiliki daya tarik yang lebih besar dibandingkan dengan perusahaan serupa lainnya, sehingga nasabah bersedia memberikan keputusan pengambilan kredit hanya pada PT. SMS Finance Bengkulu, meskipun mereka mengetahui ada banyak perusahaan serupa yang bersedia memberikan pinjaman terhadap nasabah.

Salah satu cara yang digunakan oleh PT. SMS Finance Bengkulu untuk memperoleh nasabah yang bersedia untuk melakukan pengambilan kredit pada PT. SMS Finance Bengkulu adalah dengan mengetahui nilai apa yang diberikan oleh nasabah maupun calon nasabah terhadap PT. SMS Finance Bengkulu sehingga PT. SMS Finance Bengkulu dapat mengevaluasi apa saja yang menjadi kekurangan PT. SMS Finance Bengkulu dan bersedia memperbaiki kekurangan tersebut agar calon nasabah maupun nasabah memberikan nilai yang baik sesuai dengan harapan PT. SMS Finance Bengkulu.

Menurut Hasan (2013:308) nilai bukan sesuatu yang riil, nilai sangat abstrak, nilai berasal dari persepsi konsumen mengenai berapa jumlah sebenarnya yang wajar jika dihargai dengan uang mengenai 
suatu produk yang dilihat dari mutunya. Berdasarkan pernyataan tersebut maka kewajiban PT. SMS Finance Bengkulu agar calon nasabah maupun nasabah memberikan nilai yang baik adalah dengan berupaya untuk memberikan pelayanan dan kualitas produk yang terbaik kepada calon nasabah maupun nasabah PT. SMS Finance Bengkulu.

Sama halnya dengan penjualan produk lainnya, penjualan produk jasa juga menerapkan teori pengambilan keputusan, dimana teori pengambilan keputusan yang dimaksud menurut Tjiptono (2010:156) adalah tindakan individu yang secara langsung atau tidak langsung terlibat dalam usaha memperoleh dan menggunakan suatu produk atau jasa yang dibutuhkan.

Nilai yang harus ditingkatkan oleh PT. SMS Finance Bengkulu dalam diri nasabah terhadap PT. SMS Finance Bengkulu adalah nilai emosional nasabah, diketahui bahwa PT. SMS Finance Bengkulu telah merasa bahwa PT. SMS Finance Bengkulu telah memberikan perasaan positif atas produk yang ditawarkan oleh PT. SMS Finance Bengkulu, nasabah merasa bahwa produk yang diberikan oleh PT. SMS Finance Bengkulu dalam keadaan baik dan sesuai dengan apa yang sedang dibutuhkan oleh nasabah saat ini.

PT. SMS Finance Bengkulu juga berupaya meningkatkan nilai sosial bagi PT. SMS Finance Bengkulu dengan nasabah maupun calon nasabahnya, sehingga nasabah merasa bahwa produk yang diberikan oleh PT. SMS Finance Bengkulu mampu untuk memecahkan masalah keuangan nasabah saat ini, tanpa harus membebani nasabah terlalu berat karena nasabah merasa nasabah masih mampu untuk membayar agunan kreditnya.

Dalam hal quality performance yang dirasakan oleh nasabah terhadap PT. SMS Finance Bengkulu, diketahui bahwa nasabah merasa bahwa biaya yang di ajukan oleh PT. SMS Finance Bengkulu masih mampu untuk dijangkau oleh nasabah, selain itu PT. SMS Finance Bengkulu juga memberikan tempo pembayaran kredit yang telah sesuai dengan kesepakatan nasabah.

Nasabah PT. SMS Finance Bengkulu merasa bahwa dengan mengambil kredit pinjaman pada PT. SMS Finance Bengkulu maka nasabah tidak merasa dirugikan secara finansial, karena suku bunga yang diberikan dinilai kompetitif dan adapun biaya-biaya yang ditanggung oleh nasabah ketika pelaksanaan peminjaman uang tidaklah terlalu memberatkan nasabah dan dirasa sebanding dengan apa yang didapat oleh nasabah PT. SMS Finance Bengkulu.

Nilai yang diberikan oleh nasabah PT. SMS Finance Bengkulu memberikan kesempatan bagi PT. SMS Finance Bengkulu untuk meningkatkan jumlah nasabahnya, ini dikarenakan calon nasabah bersedia untuk melakukan peminjaman kredit pada PT. SMS Finance Bengkulu. Nasabah memiliki kesadaran untuk memahami apa yang dibutuhkan dan mengetahui dengan benar produk apa yang cocok bagi nasabah sebelum melakukan peminjaman kredit pada PT. SMS Finance Bengkulu.

Nasabah melakukan pencarian beberapa referensi sebelum memutuskan mengambil kredit pada PT. SMS Finance Bengkulu serta mencari informasi selengkap-lengkapnya, dengan demikian nasabah tidak akan merasa kecewa setelah memutuskan untuk mengambil pinjaman kredit pada PT. SMS Finance Bengkulu.

Dengan banyaknya informasi yang diberikan oleh berbagai perusahaan kepada nasabah maka nasabah memiliki beberapa pilihan sebelum menjatuhkan pilihan pada PT. SMS Finance Bengkulu, dengan adanya banyak pilihan maka nasabah akan lebih leluasa untuk melakukan perbandingan yang matang sebelum memutuskan untuk melakukan pinjaman kredit.

Nasabah PT. SMS Finance Bengkulu merupakan nasabah yang telah merasa yakin bahwa produk yang ditawarkan oleh PT. SMS Finance Bengkulu adalah produk yang terbaik dari seluruh produk yang diberikan oleh perusahaan yang bergerak di bidang serupa, sehingga kekecewaan yang tidak diharapkan oleh nasabah maupun PT. SMS Finance Bengkulu dapat diminimalisir karena nasabah merasa bahwa pengambilan kredit yang dilakukan pada PT. SMS Finance Bengkulu merupakan sebuah keputusan yang sangat tepat.

\section{KESIMPULAN}

1. Nilai rho hitung $(\rho)$ adalah 0,829 berada pada interval koefisien korelasi antara $0,800-1,000$, tingkat hubungan yang sangat kuat, artinya hubungan customer value dengan keputusan pengambilan kredit pada PT. SMS Finance Bengkulu adalah sangat kuat.

2. Nilai rho hitung lebih besar dari rho tabel $(0,829>0,364)$ sehingga Ho ditolak dan Ha diterima, artinya ada hubungan yang signifikan antara customer value dengan keputusan pengambilan kredit pada PT. SMS Finance Bengkulu. 


\section{SARAN}

Mengingat Customer value yang baik merupakan aset berharga bagi PT. SMS Finance Bengkulu agar tetap berdiri dan menjalankan tujuan utamanya dengan baik, maka dari itu PT. SMS Finance Bengkulu diharapkan dapat memberikan nilai konsumen yang lebih superior di bandingkan dengan kompetitornya, seperti biaya pengambilan kredit dapat dijangkau oleh nasabah dan sebanding dengan manfaat fasilitas kredit yang diperoleh nasabah serta tempo keterlambatan pembayaran kredit tidak memberatkan nasabah.

\section{DAFTAR PUSTAKA}

Andy. 2011. Hubungan Tingkat Pelayanan Terhadap Kepuasan Nasabah Pada PT Bank Bengkulu Cabang Arga Makmur. Program Studi Manajemen Fakultas Ekonomi Universitas Dehasen Bengkulu.

Griffin, Jill. 2007. Customer loyalty: Menumbuhkan Dan Mempertahankan Kesetiaan Pelanggan. Jakarta:Erlangga

Hasan, Ali. 2013. Marketing. Yogyakarta : Media Utama

Harwan, Anri. 2012. Hubungan Pelayanan Dengan Kepuasan Nasabah Pada PT. Asuransi (Persero) Ekspor Indonesia Kantor Pemasaran Bengkulu. Program Studi Manajemen Fakultas Ekonomi Universitas Dehasen Bengkulu.

Kotler, Philip . 2008. Manajemen Pemasaran. Jakarta : PT Indeks

Kotler, Philip dan Keller Kevin Lane. 2012. Dasar-Dasar Pemasaran. Alih Bahasa Benjamin Moelan. PT. Indeks:Jakarta

Priansa, Donni Juni. 2016. Perilaku Konsumen. Bandung : Alfabeta

Manap, Abdul. 2016. Revolusi Manajemen Pemasaran. Jakarta : Mitra Wacana Media

Sopiah dan Sangadji, Etta Mamang. 2013. Perilaku Konsumen. Yogyakarta : Andi

Sugiyono, 2009. Metode Penelitian Kuantitatif Kualitatif. Bandung : Alfabeta

Mulyono, Teguh Pujo. 2007. Manajemen Perkreditan. Yogyakarta : BPFE

Tjiptono, Fandy. 2010. Manajemen Jasa. Yogyakarta : Andi Offset 